\title{
Progress on PRONGHORN Application to NGNP Related Problems
}

H. Park

D. Knoll

H. Sato

W. Taitano

August 2009
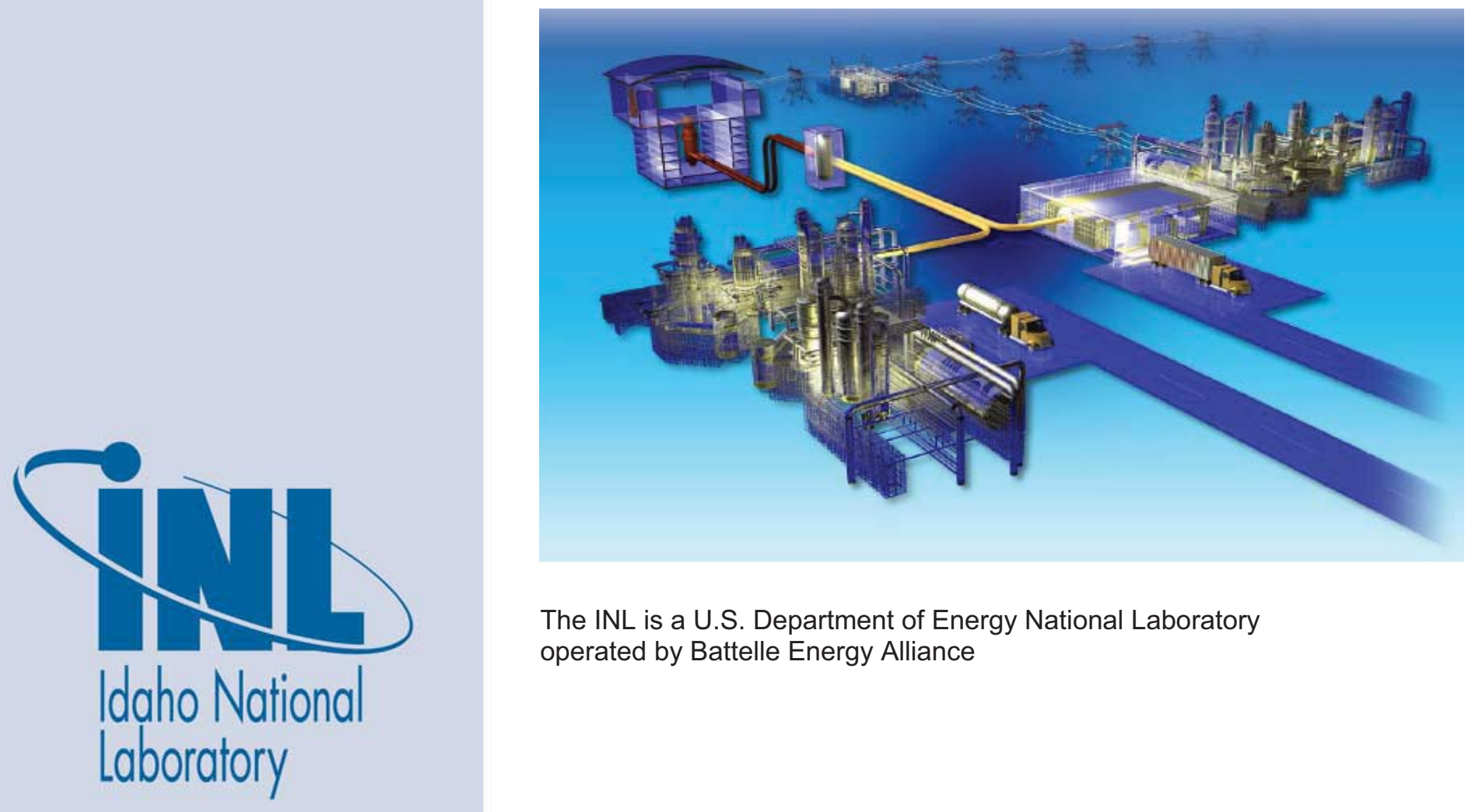

The INL is a U.S. Department of Energy National Laboratory operated by Battelle Energy Alliance 
INL/EXT-09-16659

\title{
Progress on PRONGHORN Application to NGNP Related Problems
}

\author{
H. Park \\ D. Knoll \\ H. Sato \\ W. Taitano
}

August 2009

\author{
Idaho National Laboratory \\ Next Generation Nuclear Plant Project \\ Idaho Falls, Idaho 83415
}

http://www.inl.gov

Prepared for the

U.S. Department of Energy

Office of Nuclear Energy

Under DOE Idaho Operations Office

Contract DE-AC07-05ID14517 


\section{DISCLAIMER}

This information was prepared as an account of work sponsored by an agency of the U.S. Government. Neither the U.S. Government nor any agency thereof, nor any of their employees, makes any warranty, expressed or implied, or assumes any legal liability or responsibility for the accuracy, completeness, or usefulness, of any information, apparatus, product, or process disclosed, or represents that its use would not infringe privately owned rights. References herein to any specific commercial product, process, or service by trade name, trade mark, manufacturer, or otherwise, does not necessarily constitute or imply its endorsement, recommendation, or favoring by the U.S. Government or any agency thereof. The views and opinions of authors expressed herein do not necessarily state or reflect those of the U.S. Government or any agency thereof. 

Next Generation Nuclear Plant Project

Progress on PRONGHORN Application to NGNP Related Problems

INL/EXT-09-16659

August 2009

Approved by:
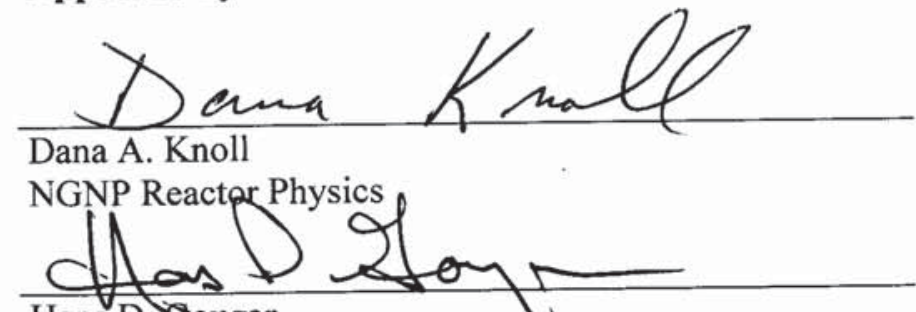

Hans

VHTR TDO Deputy Technical Director

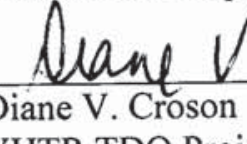

VHTR TDO Project Manager 



\begin{abstract}
A multiphysics simulation tool named PRONGHORN is being developed for very high temperature gas-cooled reactors. The tool is intended to take advantage of the Multiphysics Object-Oriented Simulation library, and be capable of solving multidimensional thermal-fluid and neutronics problems implicitly in parallel. Expensive Jacobian matrix formation will alleviated by the Jacobianfree Newton-Krylov method, and a physics-based preconditioning will be applied to improve the convergence. The initial development of PRONGHORN has focused on the pebble bed core concept, but extensions required to simulate prismatic cores are underway. This report highlights progress on application of PRONGHORN to PBMR400 benchmark problems, extension and application of PRONGHORN to prismatic core reactors, and progress on simulations of 3-D transients.
\end{abstract}




\section{CONTENTS}

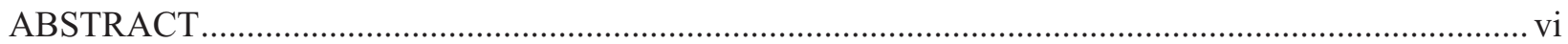

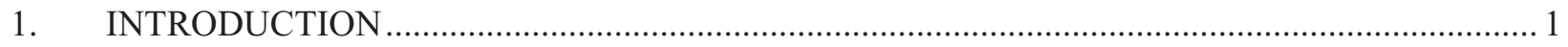

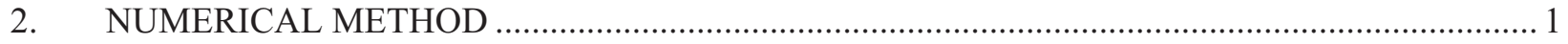

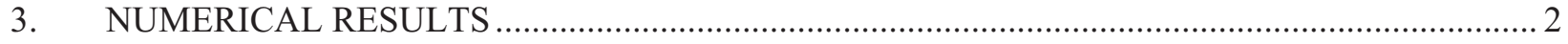

3.1 PBMR400 Bench Mark Problems................................................................................... 2

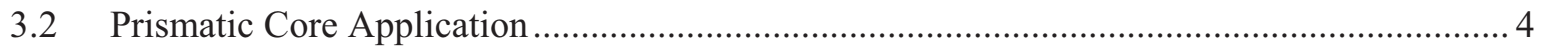

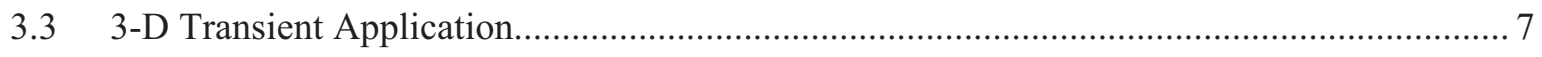

4. CURRENT LIMITATIONS OF PRONGHORN ..................................................................... 9

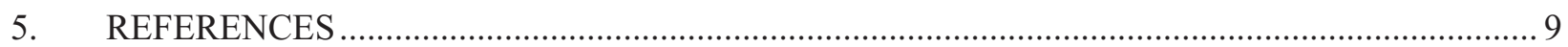

\section{FIGURES}

Figure 1. Schematic of the PBMR400 benchmark problem. .................................................................. 3

Figure 2. \$k_\{eff $\$$ comparison of the PBMR400 benchmark problem.................................................... 3

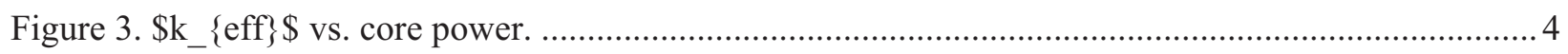

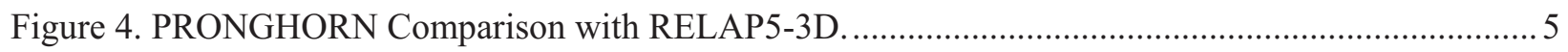

Figure 5. Fluid temperature using constant input core power density. ................................................ 6

Figure 6. Fluid temperature using self-consistent neutronics. ........................................................... 6

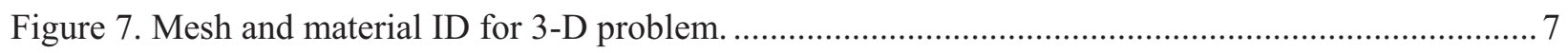

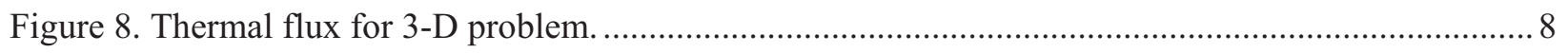

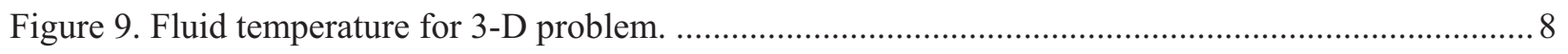

Figure 10. Power and maximum solid temperature time history from PBMR. ….................................. 8 


\section{Progress on PRONGHORN Application to NGNP Related Problems}

\section{INTRODUCTION}

PRONGHORN ${ }^{1}$ is designed to be a fully-implicit multiphysics application code targeting analysis of multiphysics phenomena for VHTRs (both pebble bed and prismatic core concepts). Current capabilities of PRONGHORN include solving steady-state coupled fluid flow-heat transfer problems and standard multigroup diffusion problems (fixed-source, criticality, and time-dependent). Both physics can be solved in multidimensional Cartesian coordinates and 2-D cylindrical (R-Z) coordinates, with precursor and adiabatic thermal feedback models.

PRONGHORN is being developed within the MOOSE framework. ${ }^{2}$ MOOSE is a software library interfacing physics applications with numerical libraries such as LIBMESH ${ }^{3}$ or PETSc ${ }^{4}$. MOOSE allows the development of physics-specific codes by abstracting linear and nonlinear solver implementations. The object-oriented nature of MOOSE allows one to quickly develop implicitly coupled physics simulations in 3-D, with parallel execution. Each physic is encapsulated as a "kernel," and each "kernel" consists of two components: evaluation of the nonlinear residual, and computation of the preconditioning matrix or approximate Jacobian. The discretized (weak) form of each kernel is implemented separately in order to provide the flexibility to test different combinations of physics.

The Jacobian-free Newton-Krylov (JFNK) method $^{5}$ is used to solve the nonlinear systems implicitly, without forming the expensive (if not impossible) Jacobian matrix. A standard finite-element spatial discretization is employed for high-order convergence. Computational burden of the implicit methods are reduced by implementation of a physics-based preconditioner $(\mathrm{PBP})^{5}$ that takes advantages of commonly used operator-split, and/or semi-implicit algorithms to improve the convergence of Krylov methods.

This report covers the governing equations and numerical algorithm as described in Section 2, and the current capabilities of PRONGHORN as demonstrated in Section 3.

\section{NUMERICAL METHOD}

The following set of PDEs are used to represent the physics of pebble bed reactors:

\section{Fluid Medium}

$$
\begin{aligned}
& \frac{\partial \epsilon \rho_{f}}{\partial t}+\nabla \cdot c \rho_{f} \vec{u}=0 \\
& \epsilon \nabla P-\epsilon \rho_{f} \vec{g}+W \rho_{f} \vec{u}=0 \\
& \frac{\partial}{\partial t}\left[c \rho_{f} c_{p f} T_{f}\right]+\nabla \cdot\left(c \rho_{f} c_{p f} \vec{u} T_{f}\right)-\nabla \cdot \kappa_{f} \nabla T_{f}+\alpha\left(T_{f}-T_{s}\right)=0
\end{aligned}
$$

\section{Solid Medium}

$$
\frac{\partial}{\partial t}\left[(1-c) \rho_{s} c_{p s} T_{s}\right]-\nabla \cdot \kappa_{s c f f} \nabla T_{s}-\alpha\left(T_{f}-T_{s}\right)-Q=0
$$




\section{Neutronics}

$$
\frac{1}{v_{g}} \frac{\partial \phi_{g}}{\partial t} \nabla \cdot D_{g} \nabla \phi_{g}+\Sigma_{R g} \phi_{g}-(1-\beta) \chi_{g} \sum_{g^{\prime}=1} \nu \Sigma_{f g^{\prime}} \phi_{g^{\prime}}-\sum_{g^{\prime}=1, g^{\prime} \neq g} \Sigma_{s}^{g^{\prime} \rightarrow g} \phi_{g^{\prime}}-\sum_{k} \lambda_{k} C_{k}=0
$$

$$
\frac{d C_{k}}{d t}+\lambda_{k} C_{k}-\beta_{k} \chi_{g} \sum_{g^{\prime}=1} \nu \Sigma_{f g^{\prime}} \phi_{g^{\prime}}=0
$$

These equations represent continuity, momentum, fluid and solid energy, and neutron diffusion equations; and precursor concentration equations, respectively. The momentum equation is approximated using Darcy's law. The coefficients such as thermal conductivities, heat transfer coefficient, and neutron cross sections are generally (strong) functions of the dependent variables, and the KTA standard ${ }^{6}$ is used to compute material properties. For more details on the models and algorithms as they pertain to a pebble bed core, consult Reference 1.

This model has also been extended in order to simulate a prismatic core. This requires a modification of the thermal model, while no modification is required for a neutronics model (with the exception of appropriate cross sections). In the thermal model, the porosity was set to 1 and a RELAP5-3D friction model was adopted for the 1-D axial flow to model coolant flow through the effective area of the set of flow channels. The porosity in the remaining equations represent the effective flow channel area. The friction factor employed is tuned so as to provide the appropriate pressure drop through a prismatic core for the appropriate mass flow rate.

\section{NUMERICAL RESULTS}

\subsection{PBMR400 Bench Mark Problems}

Results of PBMR400 benchmark problems ${ }^{7}$ are selected in order to demonstrate the neutronics and multiphysics capability of PRONGHORN. The problem is 2-D cylindrical geometry with a $2.925 \mathrm{~m}$ radius and a $14.5 \mathrm{~m}$ height. There are 190 materials in the computational domain. Figure 1 shows the schematic of the problem, while the comparison of k_eff with different codes is shown in Figure 2. The PRONGHORN result $(\mathrm{k}$ _eff $=1.00465)$ matches well with other codes. Figure 3 plots a number of multiphysics eigenvalue calculations in which the normalizing power is varied. There are only two regions in this problem; core and reflector. The plot demonstrates that as a result of thermal feedback, $\mathrm{k}$ _eff goes down as the solid temperature increases. 


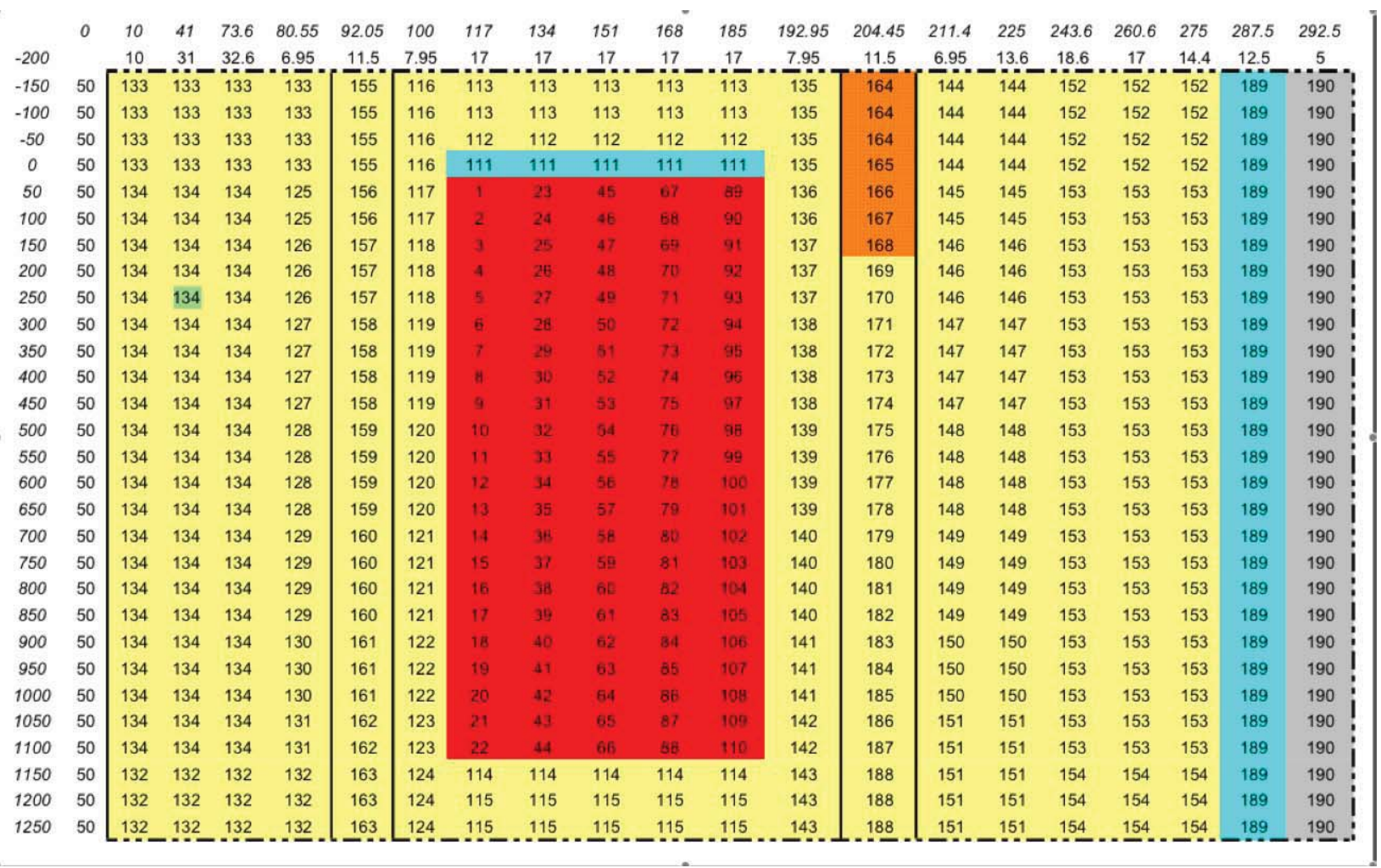

Figure 1. Schematic of the PBMR400 benchmark problem.

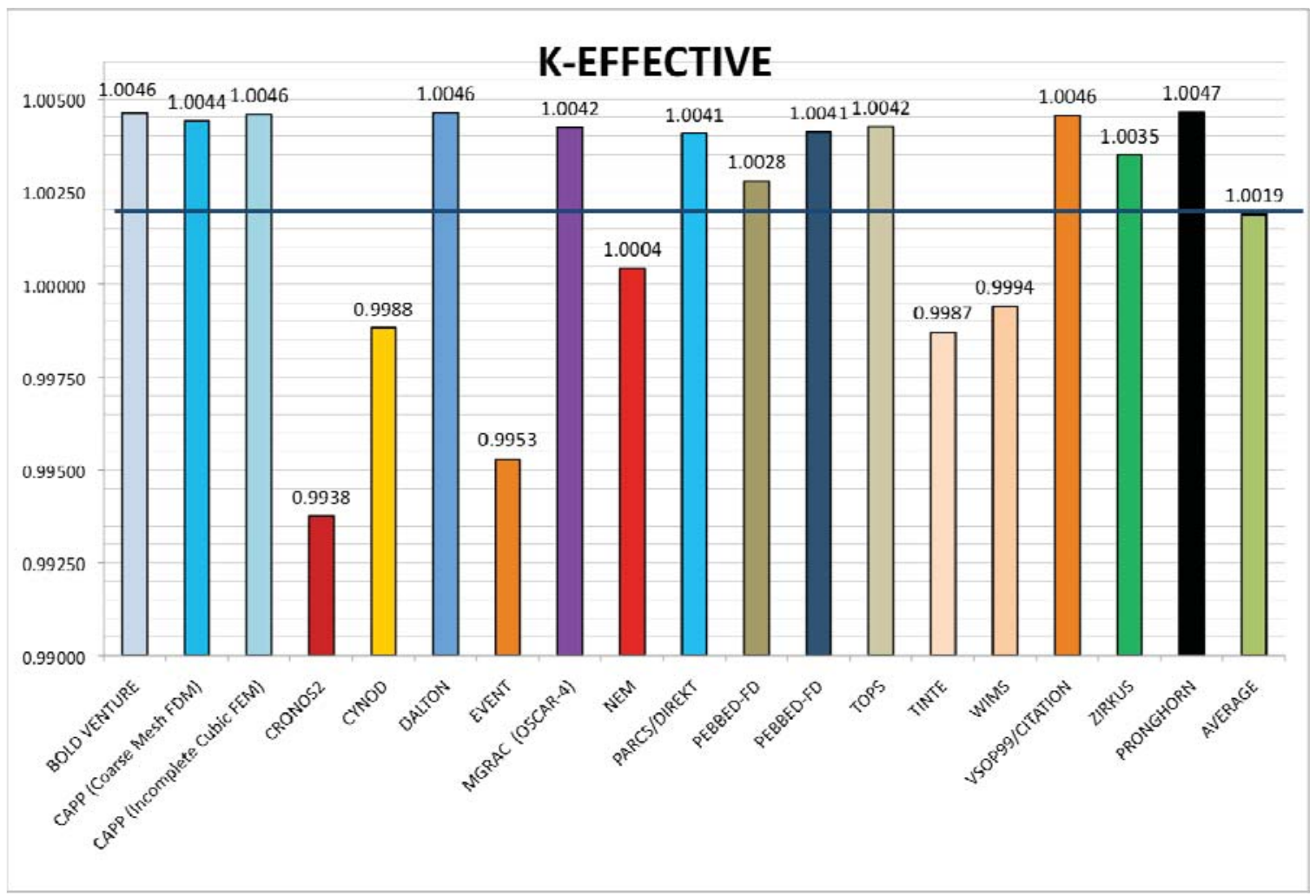

Figure 2. \$k_\{eff $\$$ comparison of the PBMR400 benchmark problem. 


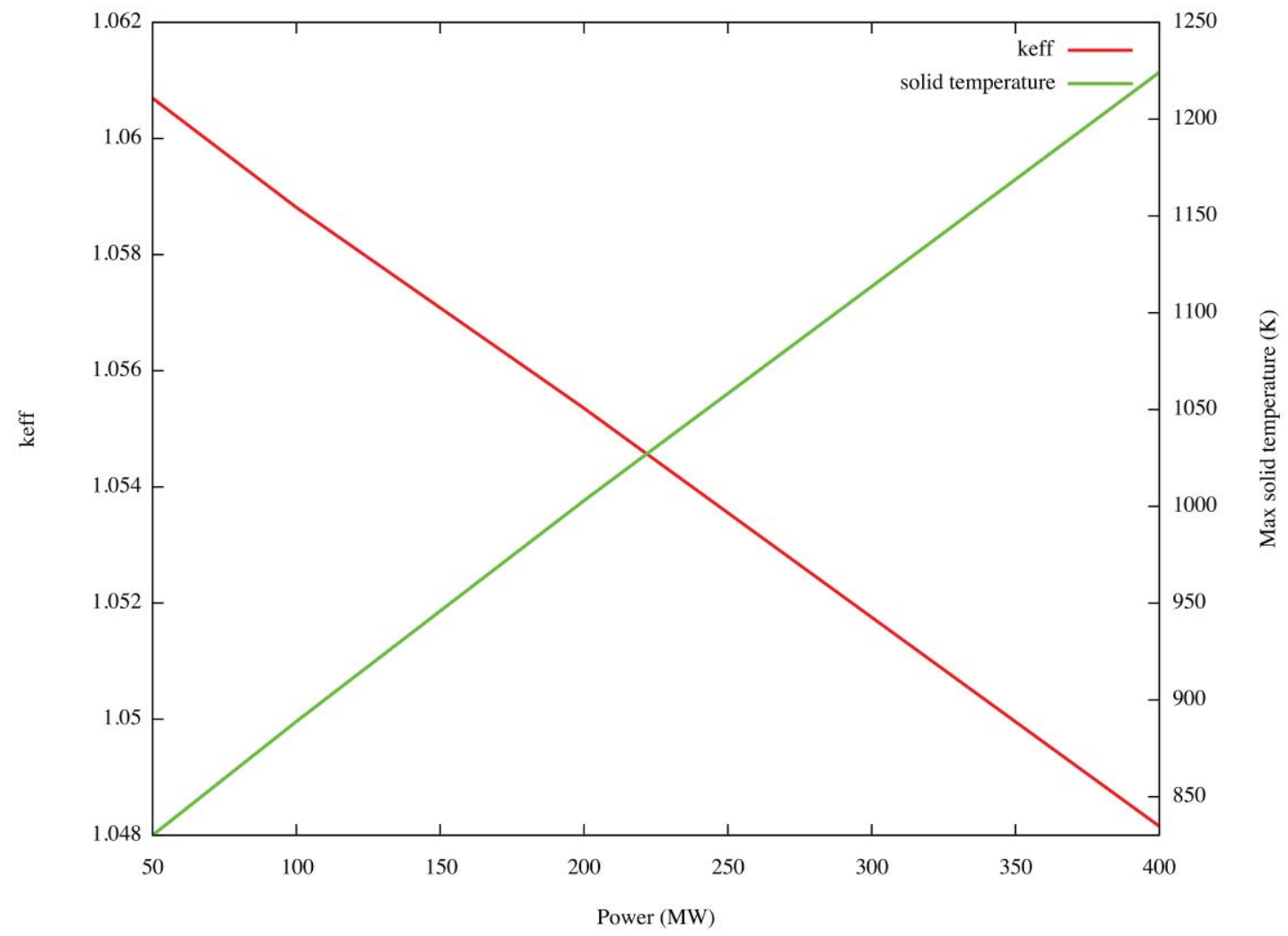

Figure 3. \$k_\{eff $\}$ vs. core power.

\subsection{Prismatic Core Application}

As stated above, an effort to extend the PRONGHORN model so that it applies to prismatic core designs has been initiated. This report shows a few examples of results from this effort to date. A more complete report devoted to this subject is currently being prepared.

In the present study, a gas turbine modular helium reactor (GTMHR; General Atomics 1996) is selected as a reference reactor for the calculations. It is a helium-cooled, graphite-moderated, thermal neutron spectrum reactor with $600 \mathrm{MW}$ thermal power. Detailed specification for these simulations can be found in a report currently in preparation at the INL. A 2-D steady-state problem has been simulated in two ways:

- A fixed core volumetric power generation rate was used to perform a stand-alone thermal analysis. These results were compared with a RELAP-3D simulation run in a similar manner. Figure 4 compares axial plots of coolant temperature in the reflector and core. This serves as a credible first assessment of the prismatic capabilities in PRONGHORN.

- A second simulation the core power was computed self-consistently with a four-group neutronics calculation fully coupled with the thermal calculations (multiphysics). At this point, these simulations only contain one-way coupling, there is no thermal feedback on the cross sections used.

Figures 5 and 6 compare the coolant temperature distributions for a uniform input power density and a more self-consistent neutronically generated power density. Again for more details on all of the results related to the PRONGHORN prismatic extension effort will be available in a more detailed report currently in preparation at the INL. 

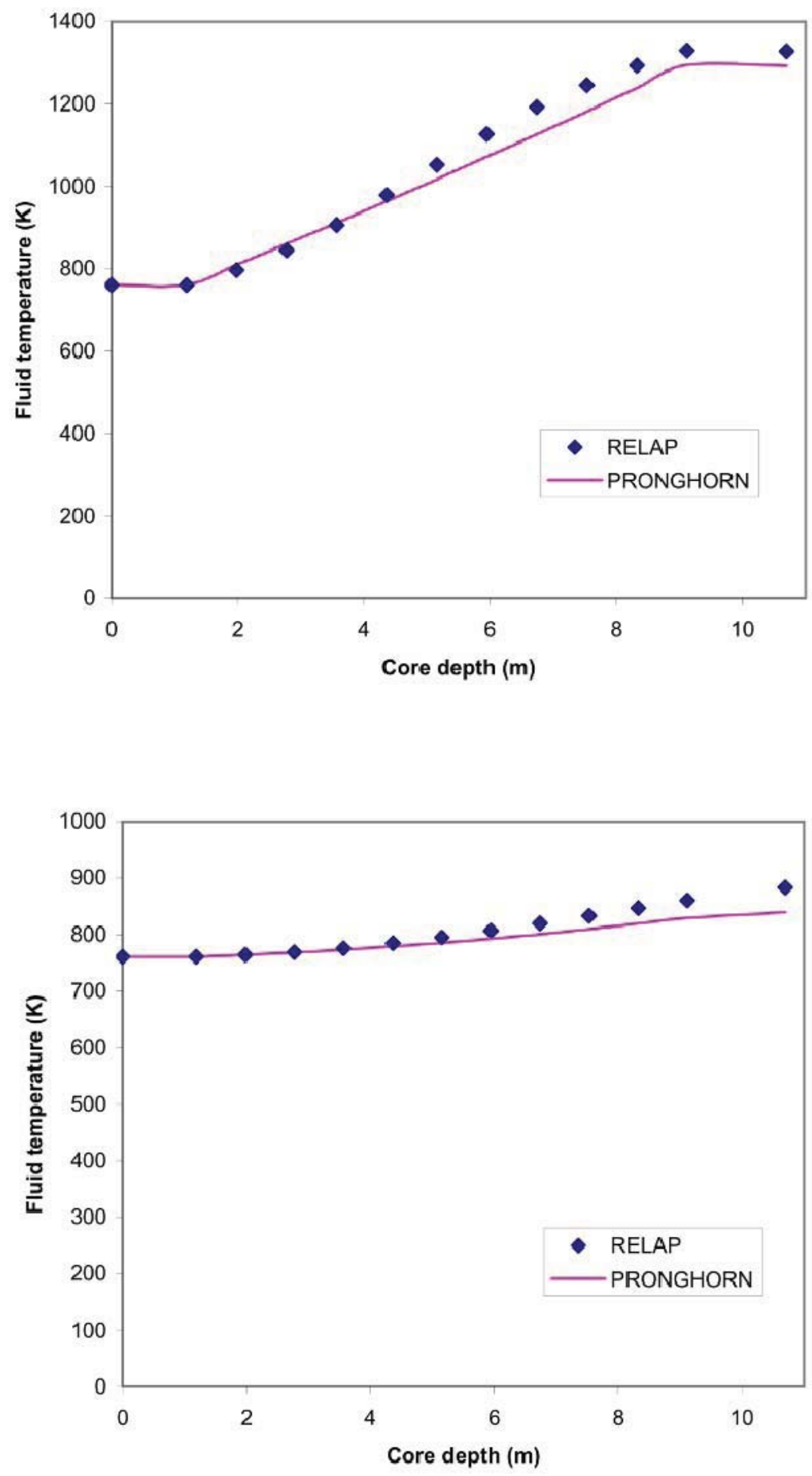

Figure 4. PRONGHORN Comparison with RELAP5-3D. 


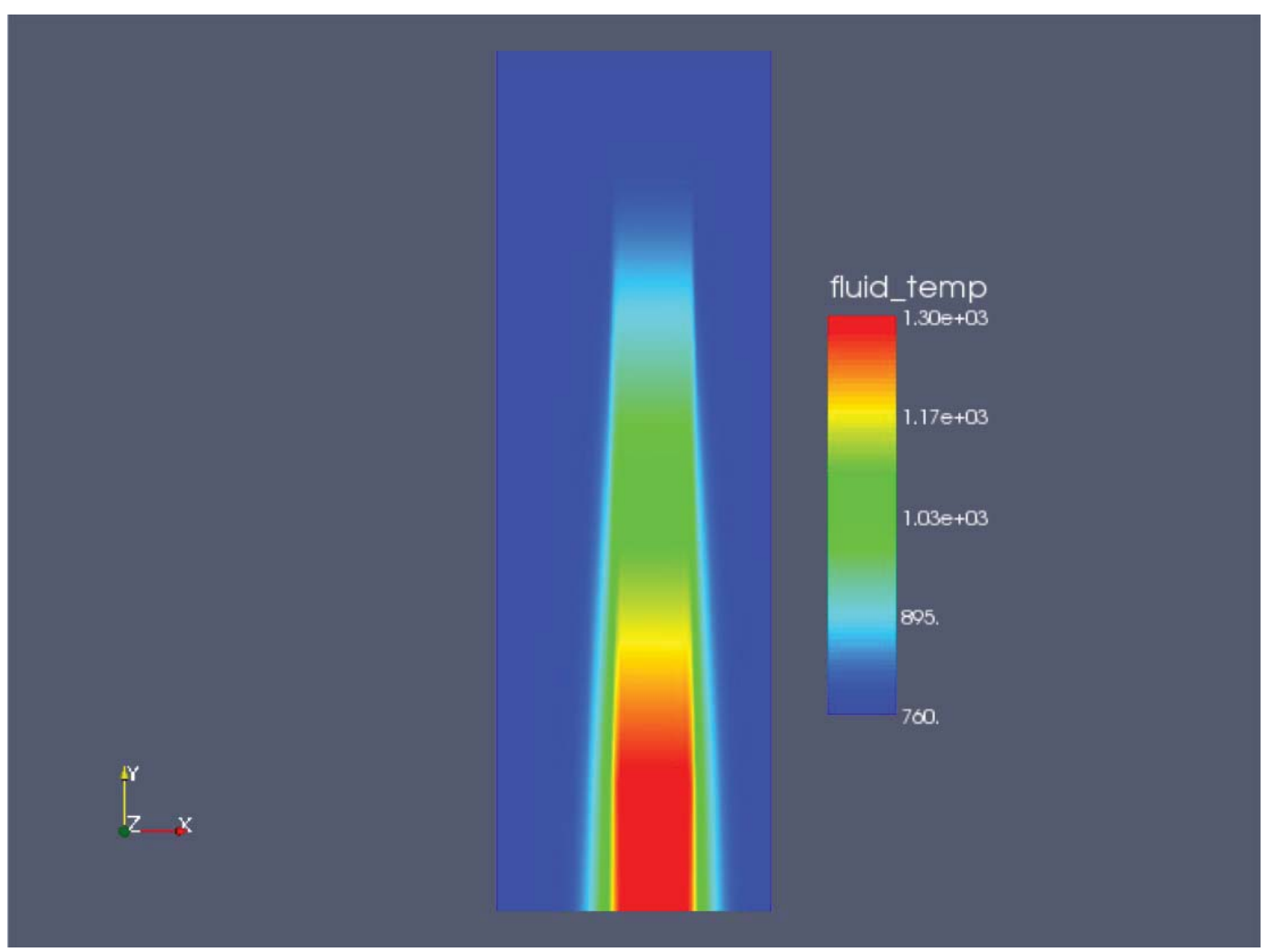

Figure 5. Fluid temperature using constant input core power density.

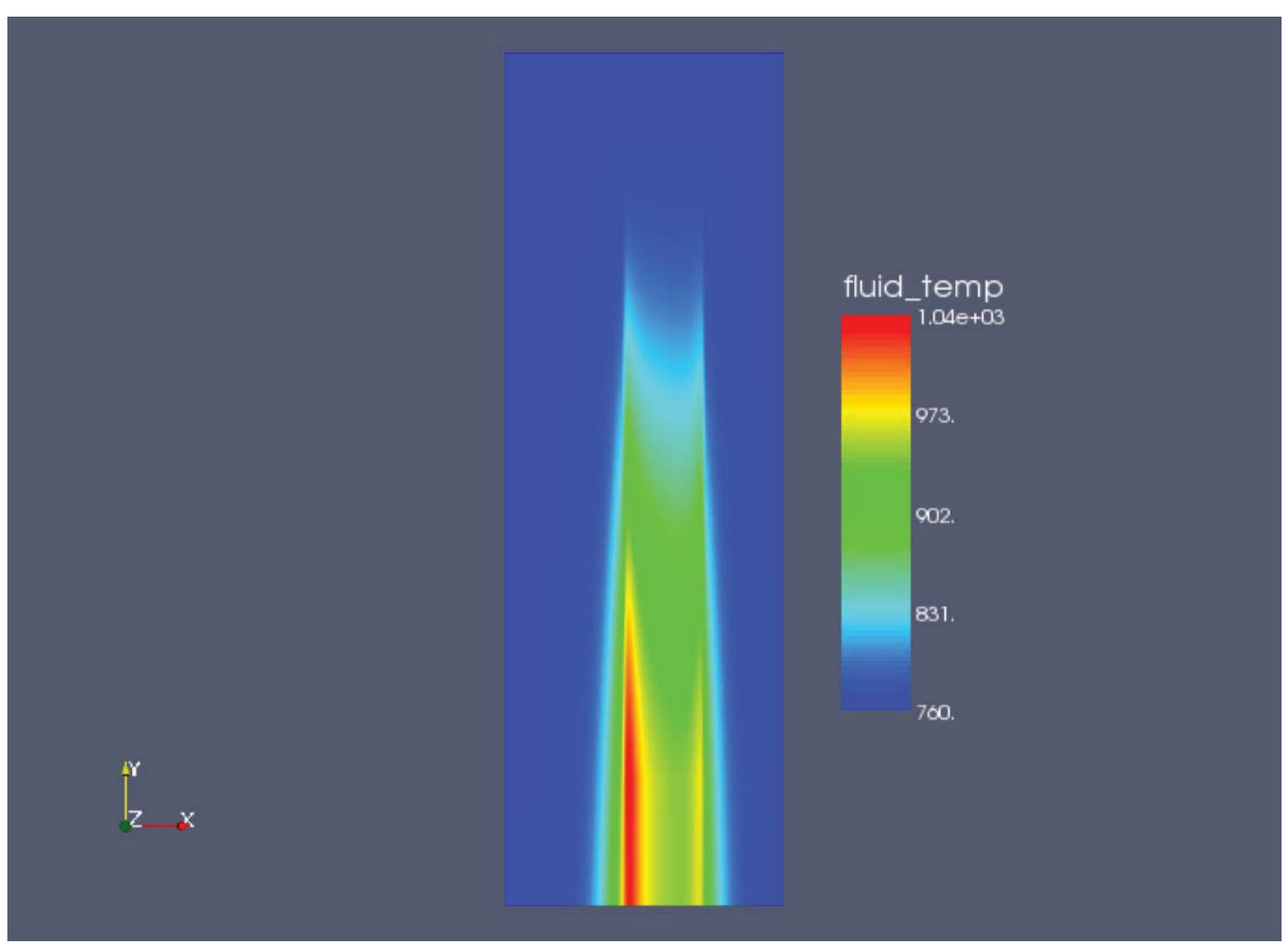

Figure 6. Fluid temperature using self-consistent neutronics. 


\subsection{3-D Transient Application}

The final goal is to complete a 3-D transient PBMR 400 rod ejection transient by the end of FY 2009. To date, a 3-D multiphysics eigenvalue calculation and a 2-D model simulation or rod-ejection transient has been completed. Some results are presented below for each simulation.

Figure 7 presents the mesh and colored material ID for a 3-D PMBR 400 multiphysics eigenvalue calculation. The mesh contains 30,000 elements so a multiphysics eigenvalue calculation on this mesh requires approximately 4 hours on four processors. The majority of this time results from the fact that there is not yet acceleration in the power iteration in a multiphysics setting. At this point, the simulation is symmetric in the theta direction but is done in 3-D.

Figures 8 and 9 plot the thermal flux and the fluid temperature, which show that the R-Z structure in the thermal flux (and thus fission source) has resulted in an interesting R-Z structure in the fluid temperature.

A preliminary study of 2-D PBMR 400 control rod ejection simulation was conducted in order to demonstrate PRONGHORN's capability to preform a multiphysics reactor kinetics simulation. Figure 10 is a plot of power and maximum solid temperature time history from PBMR 400 2-D control rod ejection simulation. The simulation shows that the thermal absorption cross section of the control rod in the 2-D PBMR 400 model problem was ramped from $9.0 \times 10^{\wedge}\{-3\} \mathrm{cm}^{\wedge}\{-1\}$ down to $1.0 \times 10^{\wedge}\{-4\} \mathrm{cm}^{\wedge}\{-1\}$ in a linear fashion over 0.1 seconds. We can see the rapid power rise, followed by the solid temperature rise, the resulting Doppler feedback, and the approach to a new core power level all over a 60 second period. These general trends and time scales are all in approximate agreement with the published PBMR 400 simulations of this type of transient by others.

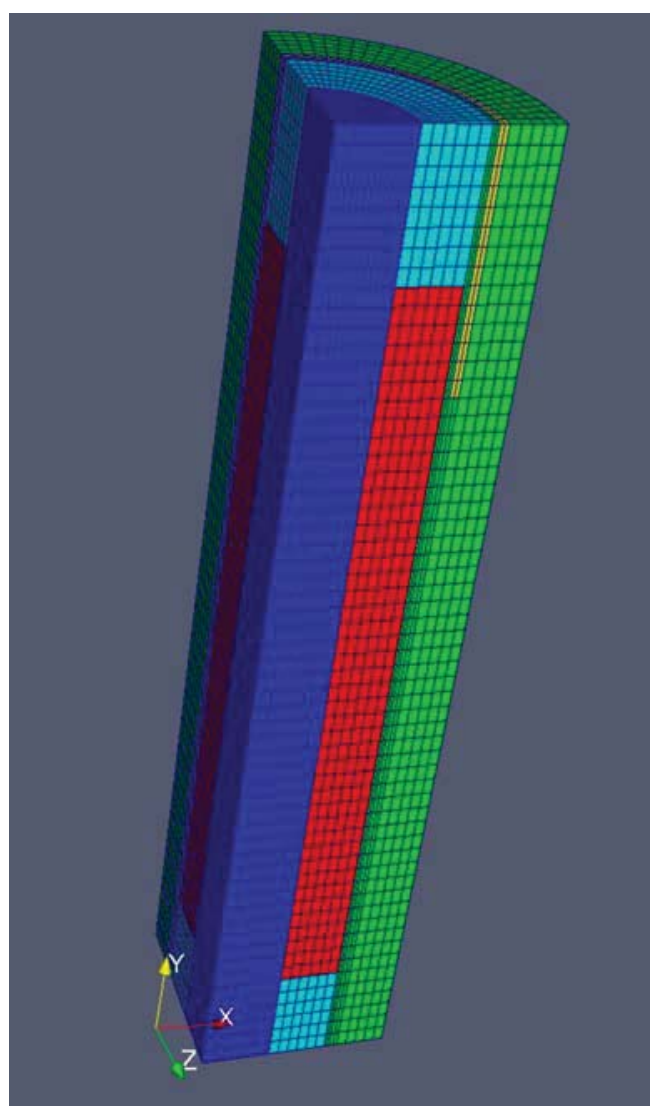

Figure 7. Mesh and material ID for 3-D problem. 


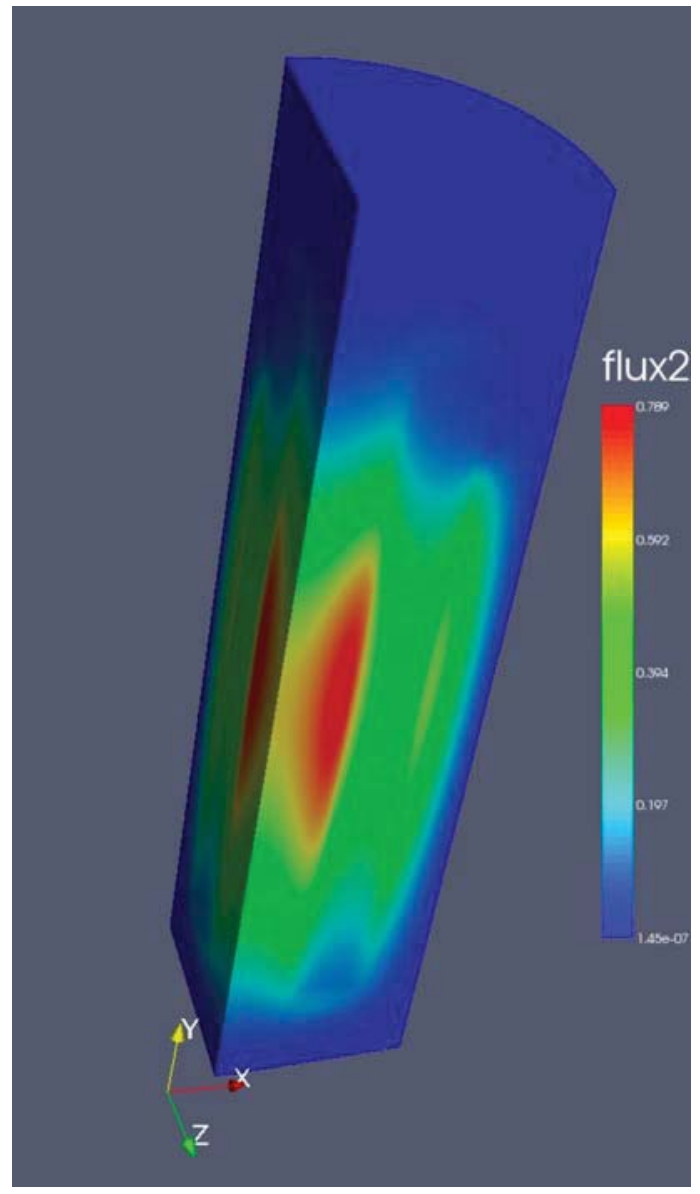

Figure 8. Thermal flux for 3-D problem.

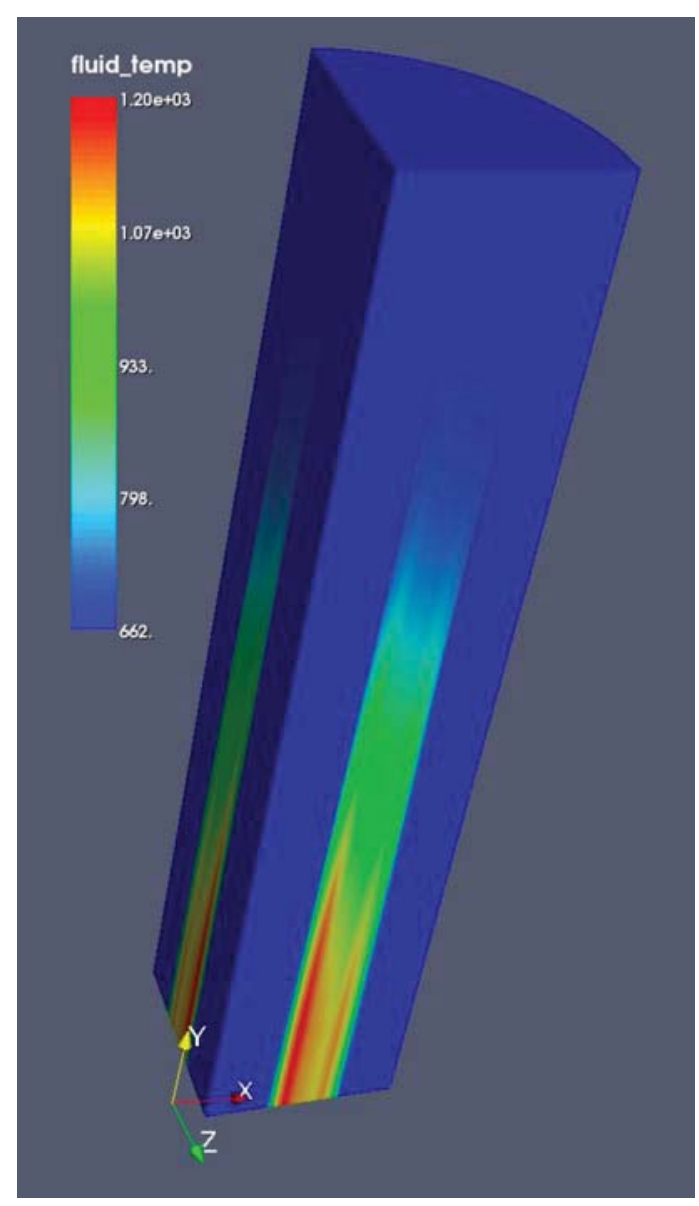

Figure 9. Fluid temperature for 3-D problem.

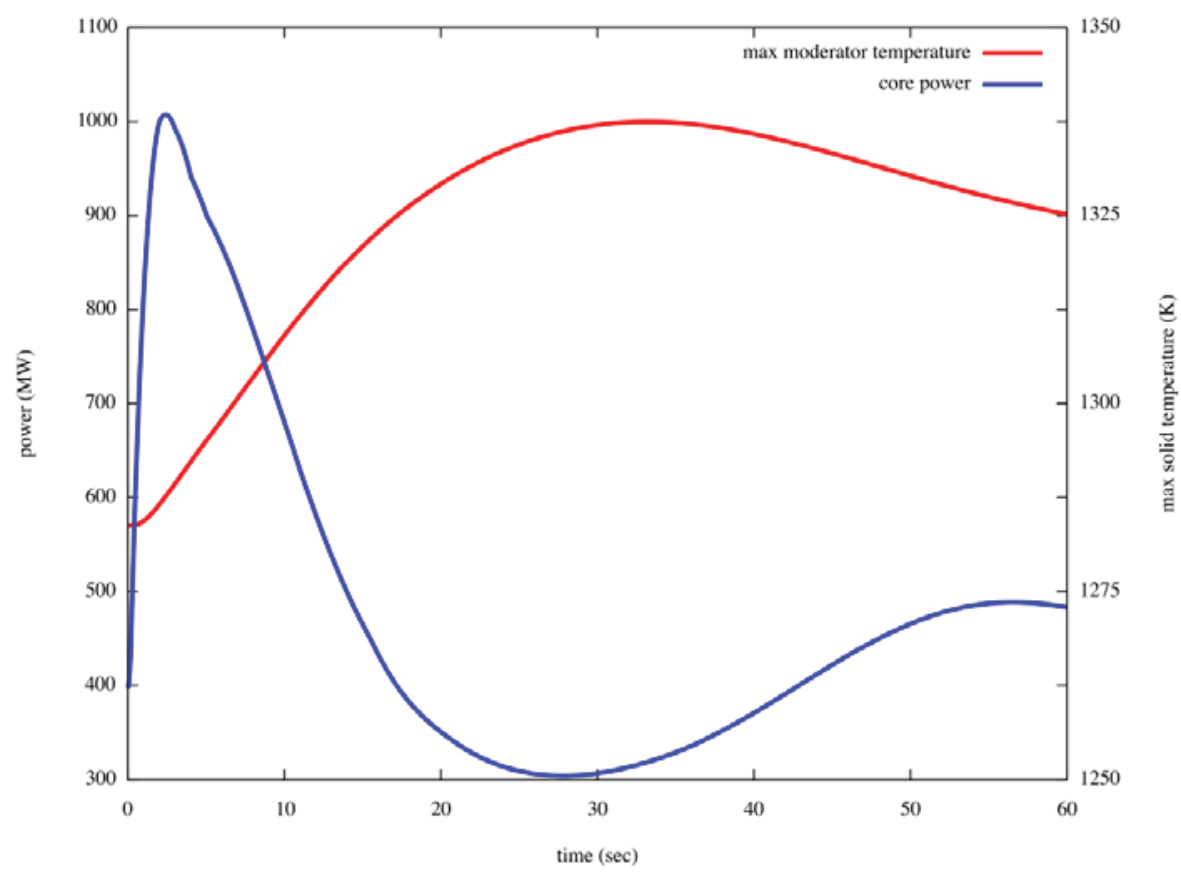

Figure 10. Power and maximum solid temperature time history from PBMR. 


\section{CURRENT LIMITATIONS OF PRONGHORN}

The current limitations of PRONGHORN, all of which will be addressed with appropriate funding over the coming year, are as follows.

- Internal boundary conditions in MOOSE, and therefore in PRONGHORN, are not being properly used. This can be fixed, but it has hindered the ability to perform exact thermal model problems for the PBMR 400 benchmark suite.

- Improved Doppler feedback (fuel temperature) model is required.

- Control rod cusping model is required.

- Thermal-flow model, which transition to porosity equal one on the core-reflector boundary, is required.

- Current neutronics model is based on diffusion theory.

\section{REFERENCES}

1. H. Park, D. Gaston, S. Kadiouglu, D. Knoll, D. Lebrun-Grandie , R. Martineau and W. Taitano", "Tightly Coupled Multiphysics Simulation for Pebble Bed Reactors," American Nuclear Society 2009 International Conference on Advances in Mathematics, Computational Methods, and Reactor Physics, Saratoga Springs, NY, May 3-7, 2009.

2. D. Gaston, C. Newman, G. Hansen and D. Lebrun-Grandi'e, Nuclear Engineering and Design, "MOOSE: A parallel computational framework for coupled systems of nonlinear equations," 2009 (in press).

3. Benjamin S. Kirk and John W. Peterson and Roy H. Stogner and Graham F. Carey, lib $\{\mathrm{M}\}$ esh: a $\{\mathrm{C}++\}$ library for parallel adaptive mesh refinement/coarsening simulations, Eng. Comput. Germany, vol 22, pp 237-254 (Jan 2006).

4. Satish Balay, Kris Buschelman, William D. Gropp, Dinesh Kaushik, Matthew G. Knepley, Lois Curfman McInnes, Barry F. Smith and Hong Zhang, http://www.mcs.anl.gov/petsc, PETSc Web page, 2001.

5. D. A. Knoll and D. E. Keyes, Jacobian-Free $\{N\}$ ewton- $\{\mathrm{K}\}$ rylov Methods: a Survey of Approaches and Applications, J. Comput. Phys., vol. 193, pp 357-397 (2004).

6. Nuclear Safety Standards Commission (KTA), Federal Republic of Germany, June, Reactor Core Design of High-Temperature Gas-Cooled Reactors, 1983.

7. Reitsma, F and Ivanov, $\mathrm{K}$ and Downar, T and de Hass, $\mathrm{H}$ and Sen, $\mathrm{S}$ and Strydom, $\mathrm{G}$ and Mphahlele, $\mathrm{R}$ and Tyobeka, B and Seker, V and Gougar, $\mathrm{H}$ and Lee, h., OECD/NEA/NSC, NEA/NSC/DOC(2007) Draft-V07, PBMR Coupled Neutronics/Thermal Hydraulics Transient Benchmark The PBMR-400 Core Design, 2007. 